\title{
Characteristics, Causes and Early Interventions for Preterm Birth - A Review Paper
}

\author{
Ritu Singh*, Niharika Bisht and Huma Parveen \\ AICRP-CD, Department of Human Development and Family Studies, College of Home \\ Science, G.B.P.U.A.\&T., Pantnagar-263145, Uttarakhand, India \\ *Corresponding author
}

\section{A B S T R A C T}

\begin{tabular}{|l|}
\hline Ke y w o r d s \\
Full term babies, \\
Gestation, \\
Immunization, Pre \\
conception care
\end{tabular}

\section{Introduction}

The normal length of pregnancy is 40 weeks (plus or minus 2 weeks) as calculated from first day of the woman's last normal menstrual cycle. The World Health Organization (WHO) defines preterm birth as any birth before 37 completed weeks of gestation, or fewer than 259 days since the first day of the woman's last menstrual period (LMP). This is further subdivided on the basis of gestational age (GA):

extremely preterm (<28 weeks); very preterm ( $28-<32$ weeks); moderate or late preterm $(32-<37$ completed weeks of gestation).
According to WHO, every year about 15 million babies are born prematurely around the world and that is more than one in 10 of all babies born globally. Premature babies are not fully equipped to deal with life in our world. Special care is needed for these babies that can provide them with the best development.

Their bodies still have underdeveloped parts that include the lungs, digestive system, immune system and skin. Many of the preterm babies suffer from various disabilities like cerebral palsy, sensory deficits, learning disabilities and respiratory illnesses. Preterm birth often extends to later life because the morbidity associated with these results in 
physical, psychological and economic stress to the individual and the family.

It has been estimated that 16 million adolescent girls between the ages of 15 and 19 give birth each year, representing approximately $11 \%$ of all births worldwide (WHO, 2007). These girls are not physically prepared for pregnancy and childbirth and without the nutritional reserves necessary are at disproportionately greater risk of having premature and low-birth weight babies (Haldre et al., 2007; Mehra, and Agrawal 2004; Paranjothy et al., 2009; WHO, 2007). Both hospital and population based studies in developed and developing countries show that adolescent girls are at increased risk for preterm birth compared with women ages 20 to 35 (Ekwo and Moawad, 2000; Khashan et al., 2010). The risk is especially high for younger adolescent girls (Khashan et al., 2010; Sharma et al., 2008).

\section{Causes of preterm birth}

\section{Maternal history}

It is a strong risk factor and most likely driven by the interaction of genetic, epigenetic and environmental risk factors (Plunkett and Muglia, 2008). Many maternal factors have been associated with an increased risk of spontaneous preterm birth, including young or advanced maternal age, short inter-pregnancy intervals and low maternal body mass index (Goldenberg et al., 2008; Muglia and Katz, 2010).

\section{Multiple pregnancies}

Another important risk factor is uterine over distension with multiple pregnancies. Multiple pregnancies (twins, triplets, etc.) carry nearly 10 times the risk of preterm birth compared to singleton births (Blondel et al., 2006).

\section{Infection}

Infection plays an important role in preterm birth. Urinary tract infections, malaria, bacterial vaginosis, HIV and syphilis are all associated with increased risk of preterm birth (Gravett et al., 2010). In addition, other conditions have recently been shown to be more associated with infection, e.g., "cervical insufficiency" resulting from ascending intrauterine infection and inflammation with secondary premature cervical shortening (Lee et al., 2008). It is a trauma to the cervix during previous abortion as a result of the use of metal tools. It may also be due to ruptures of the cervix in previous births. Due to cervical insufficiency, the internal opening of the cervix cannot endure the growing fetus during pregnancy, the cervix opens and miscarriage or premature birth occurs.

\section{Maternal lifestyle}

Some lifestyle factors that contribute to spontaneous preterm birth include stress and excessive physical work or long times spent standing (Muglia and Katz, 2010). Smoking and excessive alcohol consumption as well as periodontal disease also has been associated with increased risk of preterm birth (Gravett et al., 2010).

\section{Placenta praevia (Non-typical attachment of the placenta)}

Placenta previa is a condition in which the placenta lies very low in the uterus and covers all or part of the cervix. The most common symptom of placenta previa is painless bleeding from the vagina during the second half of pregnancy. Women with placenta previa are at increased risk for recurrent spontaneous preterm birth. It contributes to about $5 \%$ of all preterm deliveries (Salafia $e t$ al., 1992). 


\section{Age factor}

Maternal factors like young or advanced maternal age have also been associated with an increased risk of spontaneous preterm birth (Goldenberg et al., 2008).

\section{Pre-eclampsia}

Pre-eclampsia is the development of elevated blood pressure and protein in the urine after the twentieth week of pregnancy. It may results in swelling of face and hands, high blood pressure, vision disturbances, headaches, nausea and vomiting. This condition can result in serious complications to the mother and fetus and can also threaten the life of the baby and it is then necessary for the baby to be born early, even prematurely. According to a study by Davies et al., (2016) significant positive association was found between preeclampsia and preterm birth.

\section{Inadequate birth gap}

A period of less than six to nine months between the birth of one baby and the start of the next pregnancy increases the risk of premature delivery. Appropriate birth spacing after a previous live birth or pregnancy loss decreases the risk for prematurity in subsequent pregnancies (Shah and Zao, 2009).

\section{Heredity}

It may play a role in the risk of premature birth

\section{Ways of care for pre-term babies}

Preterm babies require extra care in initial days because they are not fully developed to live outside their mother's womb. This extra care and attention enables them to successfully adapt to the new environment. Some of the important ways of caring for pre term babies are discussed as under:

\section{Keeping warm}

Preterm and low birth weight babies have great difficulty in maintaining their body temperature. They very easily lose heat, and hypothermia is life-threatening in their delicate condition. It is therefore recommended that immediately after the birth, the baby must be put in skin-to-skin contact with the mother. Breast-feeding should start as soon as possible to provide calories and stimulation which will in turn help keep the infant warm. An important thing to remember is that the baby's head needs to be well covered. This is because more than $90 \%$ of the heat loss is through the head if it is left uncovered. Bathing should be delayed for at least 48 hours after delivery, and only warm water should be used (WHO, 1994).

\section{Kangaroo mother care}

It is a technique by which the baby is held on an adult's chest usually the mother with skinto-skin contact, for extended periods of time. The baby is placed on his/her mother's chest and stays there for day and night or held in place by a cloth that is wrapped and tied at the mother's back. It proves an effective way to meet a premature baby's needs for warmth, frequent breastfeeding, protection from infection, stimulation, safety and love (WHO, 2003).

\section{Breathing support}

Most very preterm infants have difficulty aerating their lungs and require respiratory support at birth. Though many preterm babies start breathing on their own but those who don't need basic newborn resuscitation; if 
breathing problems persist, they may need additional support from a machine (ventilator) and extra oxygen (WHO, 2013).

\section{Feeding support}

Early initiation of breastfeeding within one hour after birth has been shown to reduce neonatal mortality (Bhutta et al., 2008; Edmond et al., 2006; Mullany et al., 2008). Premature babies benefit from breast milk nutritionally, immunologically and developmentally (Callen and Pinelli, 2005). The short-term and long-term benefits compared with formula feeding are well established with lower incidence of infection and necrotizing enter colitis and improved neurodevelopmental outcome (Edmond et al., 2007; Hurst, 2007). Most premature babies require extra support for feeding with a cup, spoon or another device such as gastric tubes (either oral or nasal) (WHO, 2011a; Lawn et al., 2001).

\section{Infections prevention}

The immune systems of preterm babies are not fully developed therefore they are obviously more susceptible to infections and such infections significantly contribute to neo natal deaths. Infection to a new born can be transmitted through poor hygienic conditions, use of non sterile surgical instruments (for cutting the umbilical cord).

Hence maintaining a hygienic setting is of utmost importance. It should me made sure that everyone who is touching either the baby or the mother should use a sanitizer beforehand. Also the babies who have caught some infections must be treated with antibiotics.

\section{Neonatal intensive care units}

Hospitals with neonatal intensive care units can provide specialized care for newborn babies with serious health problems. They have special equipment and specially trained doctors and nurses who provide around-theclock care for preterm babies who need extra support to keep warm, to breathe and to be fed, or who are very sick (WHO, 2013)

\section{Sleep support}

Give the baby plenty of opportunity for sleep. Although premature babies sleep more hours each day than full-term babies, they sleep for shorter periods of time. All premature babies should only be put on their backs but not on their stomachs. Use of a firm mattress and no pillow is recommended (FDO, 2017).

\section{Preventing pre-term births}

Preconception care has, until recently, been a weak link in the continuum of care. Providing care to women and couples before and between pregnancies (interconception care) improves the chances of mothers and babies being healthy, and awareness is growing. Preconception care may be defined as "any intervention provided to women and couples of childbearing age, regardless of pregnancy status or desire, before pregnancy, to improve health outcomes for women, newborns and children" (Bhutta et al., 2011a), or "a set of interventions that aim to identify and modify biomedical, behavioral and social risks to a woman's health or pregnancy outcome through prevention and management" (Johnson et al., 2006). Preconception care encompasses broader initiatives such as women's education and empowerment, and more targeted health interventions. Preconception care is primarily aimed at:

Preventing pregnancy in adolescence

Preventing unintended pregnancies and promote birth spacing and planned pregnancies

Optimizing pre-pregnancy weight 
Promoting healthy nutrition including supplementation/fortification of essential foods with micronutrients

Promoting vaccination of children and adolescents

There is growing evidence that reducing risks in the preconception period improves the health of the pregnant woman and also contributes to the prevention of preterm birth. So, in the context of the same, the research team of AICRP- CD pantnagar has designed few activities to equip women with knowledge and practical ways of investing extra care for pre-term babies because for taking a right action one must be aware of the rationale behind it. The activities have been developed in a game format because gamebased learning is the new trend in education as it helps the participants acquire the desired knowledge and skills and have fun at the same time.

The activities have been discussed as under:

Activity 1 'Pretend Play'

Time

20-30 minutes (depends on no. of participants)

\section{Material required}

A doll (pretending a preterm baby)

\section{How to play}

Arrange all the participants in a circle.

Ask each one of them to hold the doll in their hands and pretend the doll as a real preterm baby.

Ask them to show how to care for preterm baby as a care taker/mother.
Repeat this passing of doll one by one to all participants.

\section{Facilitator's note}

Note down all the innovative ideas of caring for a preterm baby told by the participants.

Now share and discuss the correct ways of caring. Also discuss the reasons behind it.

In the last, applaud everyone for their inputs and participation.

\section{Activity 2 'Match the Column'}

Time

15-20 minutes

\section{Material required}

1. Required number of paper slips mentioning the characteristics of preterm baby and full term baby (Fig. 1 and 2).

2. A pen/pencil

\section{How to play}

Let all the participants to sit separately.

Distribute the paper slips to all of them.

Ask them to play the game by matching the characteristics of preterm and full term baby with the help of a pen/pencil.

Check all the responses and discuss.

In the last, applaud everyone for their participation. 
Fig.1 Question sheet

\begin{tabular}{|l|l|}
\hline \multirow{5}{*}{ FULL TERM BABY } & $\begin{array}{l}\text { Birth weight }<2.5 \\
\text { Kgs }\end{array}$ \\
\hline Child born between 37 \\
-40 weeks \\
\hline Kangaroo mother care \\
\hline Pregnancy at age 28 \\
\hline Birth weight $>2.5 \mathrm{Kgs}$ \\
\hline $\begin{array}{l}\text { Child born before 37 } \\
\text { weeks }\end{array}$ \\
\hline $\begin{array}{l}\text { Smoking and drinking } \\
\text { during pregnancy }\end{array}$ \\
\hline \begin{tabular}{l} 
Pregnancy at age 38 \\
\hline Healthy diet before \\
and during pregnancy
\end{tabular} \\
\hline
\end{tabular}

Fig.2 Answer Sheet

\begin{tabular}{|l|l|}
\hline Options & Answers \\
\hline Birth weight $<2.5 \mathrm{Kgs}$ & PRETERM BABY \\
\hline Child born between $37-40$ weeks & FULL TERM BABY \\
\hline Kangaroo mother care & PRETERM BABY \\
\hline Pregnancy at age 28 & FULL TERM BABY \\
\hline Birth weight $>\mathbf{2 . 5}$ Kgs & FULL TERM BABY \\
\hline $\begin{array}{l}\text { Child born before } 37 \text { weeks } \\
\text { Smoking and drinking during } \\
\text { pregnancy }\end{array}$ & PRETERM BABY \\
\hline $\begin{array}{l}\text { Pregnancy at age } 38 \\
\text { Healthy diet before and during } \\
\text { pregnancy }\end{array}$ & FULL TERM BABY \\
\hline
\end{tabular}

In conclusion, preterm birth is a growing concern globally. Various steps are been taken to combat this serious issue yet the magnitude of this problem is growing day by day. Despite of the advancement in science and technology, the problem still persists in large numbers. To successfully address the growing problem of preterm birth, identification of risk factors with improved care before, between and during pregnancies; better access to contraceptives and increased education plays a very crucial role. As individuals we should try to learn and gain knowledge pertaining to such issues because that would decide our future actions. Apart from that supportive government policies and initiatives can help to increase the access to quality care. Also a sound vigilance is needed to make sure that the government policies and initiatives are reaching to every quarter of the society. For this, efforts should be made at each level and only then we can make it possible for every woman to receive the care they need before, during and after the delivery. 


\section{References}

Bhutta, Z.A., Ahmed, T., Black, R.E., Cousens, S., Dewey, K., et al., (2008). What works? Interventions for maternal and child under nutrition and survival. The Lancet, 371(9610), 417440.

Blondel, B., Macfarlane, A., Gissler, M., Breart, G., and Zeitlin, J. (2006). Preterm birth and multiple pregnancy in European countries participating in the PERISTAT project. BJOG: An International Journal of Obstetrics and Gynaecology, 113(5), 528-535.

Callen, J., and Pinelli, J. (2005). A review of the literature examining the benefits and challenges, incidence and duration, and barriers to breastfeeding in preterm infants. Advanced Neonatal Care, 5(2), 72-88

Davies, E., Bell, J. and Bhattacharya, S. (2016) Preeclampsia and preterm delivery: A population-based casecontrol study. Hypertension in Pregnancy, 35 (4), 510-519.

Edmond, K.M., Zandoh, C., Quigley, M.A., Amenga-Etego, S., Owusu- Agyei, S., et al., (2006). Delayed breastfeeding initiation increases risk of neonatal mortality. Pediatrics, 117(3), e380e386.

Edmond, K.M., Kirkwood, B.R., AmengaEtego, S., Owusu-Agyei, S., and Hurt, L.S. (2007). Effect of early infant feeding practices on infection-specific neonatal mortality: an investigation of the causal links with observational data from rural Ghana. The American Journal of Clinical Nutrition, 86(4), 1126-1131.

Ekwo, E.E. and Moawad, A. (2000). Maternal age and preterm births in a black population. Paediatric and perinatal epidemiology, 14, 145-151.

Family Doctor Organization(FDO). (2017).
Caring for Your Premature Baby. Retrieved from https://familydoctor.org/caring-foryour-premature-baby/

Goldenberg, R.L., Culhane, J.F., Iams, J.D., and Romero, R. (2008). Epidemiology and causes of preterm birth. The Lancet, 371(9606), 75-84.

Gravett, M.G., Rubens, C.E., and Nunes, T.M. (2010). Global report on preterm birth and stillbirth (2 of 7): discovery science. BMC Pregnancy Childbirth, 10 Suppl 1, S2.

Haldre, K., Rahu, K., Karro, H. and Rahu, M. (2007). Is a poor pregnancy outcome related to young maternal age? A study of teenagers in Estonia during the period of major socio-economic changes (from 1992 to 2002). European Journal of Obstetrics and Gynecology and Reproductive Biology, 131, 45-51.

Howson C.P., Kinney M.V., Lawn J. March of Dimes, PMNCH, Save the Children, WHO; 2012. Born Too Soon: the global action report on preterm birth. Hurst, N.M. (2007). The 3 M's of breast-feeding the preterm infant. Journal of Perinatal and Neonatal Nursing, 21(3), 234-239.

Johnson, K., Posner, S.F., Biermann, J. Cordero, J.F., Atrash, H.K., et al., (2006). Recommendations to improve preconception health and health care United States. Morbidity and Mortality Weekly Report, Pp. 55.

Khashan, A., Baker, P. and Kenny, L. (2010). Preterm birth and reduced birth weight in first and second teenage pregnancies: a register based cohort study. BMC pregnancy and childbirth, $10,36$.

Lawn, J.E., McCarthy, B.J., and Ross, S.R. (2001). The Healthy newborn: A reference guide for program managers. Atlanta, Georgia: CDC and CARE. 
Lee, S.E., Romero, R., Park, C. W., Jun, J.K., and Yoon, B.H. (2008). The frequency and significance of intra amniotic inflammation in patients with cervical insufficiency. American Journal of Obstetrics and Gynecology, 198(6), 633 e631-638.

Mehra, S. and Agrawal, D. (2004). Adolescent health determinants for pregnancy and child health outcomes among the urban poor. Indian Pediatrics, 41, 137-45.

Mullany, L.C., Katz, J., Li, Y.M., Khatry, S.K., LeClerq, S.C., et al., (2008). Breast-feeding patterns, time to initiation, and mortality risk among newborns in southern Nepal. The Journal of Nutrition, 138(3), 599-603.

Paranjothy, S., Broughton, H., Adappa, R. and Fone, D. (2009). Teenage pregnancy: who suffers? Archives of disease in childhood, 94, 239-245.

Plunkett, J., and Muglia, L. J. (2008). Genetic contributions to preterm birth: implications from epidemiological and genetic association studies. Annals of Medicine, 40(3), 167-195.

Salafia CM, Vogel CA, Bantham KF, Vintzileos AM, Pezzullo J, Silberman L. (1992). Preterm delivery: correlations of fetal growth and placental pathology. Am J Perinatol, 9:190-193.
Shah, P.S. and Zao, J. (2009). Induced termination of pregnancy and low birth weight and preterm birth: a systematic review and meta analyses. BJOG: An International Journal of Obstetrics and Gynaecology, 116, 1425-1442.

Sharma, V., Katz, J., Mullany, L.C., Khatry, S.K., Leclerq, S.C., et al., (2008). Young maternal age and the risk of neonatal mortality in rural Nepal. Archives of Pediatrics and Adolescent Medicine, 162, 828.

WHO. (1994). Thermal Control of the Newborn: A practical guide. Geneva: World Health Organization

WHO. (2003). Kangaroo mother care: A practical guide. Geneva: World Health Organization

WHO. (2007) Pocket book of hospital care for children: guidelines of the management of common illnesses with limited resources. Geneva: World Health Organization.

WHO. (2011). Guidelines on optimal feeding of low birth weight infants in low and middle income countries. Geneva: World Health Organization.

WHO. (2013) What kind of care do preterm babies need? Retrieved from https://www.who.int/features/qa/preter m_baby_care/en/

\section{How to cite this article:}

Ritu Singh, Niharika Bisht and Huma Parveen. 2019. Characteristics, Causes and Early Interventions for Preterm Birth - A Review Paper. Int.J.Curr.Microbiol.App.Sci. 8(05): 15731580. doi: https://doi.org/10.20546/ijcmas.2019.805.182 